\title{
Recurrent Hamstring Injuries in Elite Athletes - A Paradigm Shift to Mechanical Dysfunction of the Sacroiliac Joint as One Causation
}

\author{
Jennifer Saunders ${ }^{1}$, Barbara Hungerford ${ }^{2}$, Trish Wisbey-Roth ${ }^{3}$, Mel Cusi ${ }^{1}$, Hans Van der Wall ${ }^{4, *}$ \\ ${ }^{1}$ Sydney School of Medicine, University of Notre Dame, Australia \\ ${ }^{2}$ Sydney Spine \& Pelvis Physiotherapy Centre, Australia \\ ${ }^{3}$ Bounceback Physio (www.Bounceback.physio), Australia \\ ${ }^{4} \mathrm{CNI}$ Molecular Imaging \& Sydney School of Medicine, University of Notre Dame, Sydney, Australia
}

Copyright $\subseteq 2019$ by authors, all rights reserved. Authors agree that this article remains permanently open access under the terms of the Creative Commons Attribution License 4.0 International License

\begin{abstract}
Recurrent hamstring injuries is a significant and troubling issue in the elite athletic community. Reinjury may occur in up to $34 \%$ of patients in the kicking and running sports. We hypothesised that a proportion of these patients may have mechanical dysfunction of the sacroiliac joint as a causative mechanism. We recruited 23 elite athletes with recurrent hamstring injuries and lateralising lower back pain into the study after careful screening. Diagnosis was confirmed by scintigraphic SPECT/ CT imaging. Patients who failed directed physiotherapy were offered injection of the sacroiliac joint with platelet rich plasma (PRP). All 23 athletes (Av age 35 years, $19 \mathrm{M}, 4 \mathrm{~F})$ had MRI evidence of hamstring tears (Av 4.2 tears) and met criteria for a diagnosis of sacroiliac joint dysfunction with mean clinical scores of 6.8 (Range: 7-9). Four patients returned to sport after physiotherapy and 19 underwent peri-articular PRP injection under ultrasound guidance. The baseline VAS was 80 (mean) and after treatment 9 , indicating a significant response to treatment $(\mathrm{p}=0.002)$. All patients with SIJ dysfunction and recurrent hamstring tears responded to treatment. A plausible explanation for the relationship is the alteration in muscle sequencing around the pelvis following SIJ dysfunction.
\end{abstract}

Keywords Sacroiliac, Incompetence, Hamstring, Ultrasound, SPECT/ CT, PRP

\section{Introduction}

Hamstring injuries are common in professional athletes, particularly in the rugby codes or any sport that involves kicking and running $(1,2)$. Unfortunately, re-injury is extremely common following hamstring injury, rates as high as $34 \%$ being reported by a number of authors $(3,4)$.
Furthermore, re-injury is associated with more severe symptoms and a prolonged recovery time. We have noted the prevalence of hamstring enthesopathy in the vast majority of patients with mechanical dysfunction of the sacroiliac joint (sacroiliac joint (SIJ) incompetence) (5). While hamstring enthesopathy was prevalent in the general group of patients with SIJ dysfunction, the majority of these patients were relatively symptom-free at these sites, the clinical condition being dominated by pain arising from the affected joint. Clinical examination would often demonstrate significant alterations in muscle control around the pelvis and hips. These findings were apparent in $60 \%$ of 1200 cases with mechanical dysfunction of the sacroiliac joint (6). This was in sharp contrast to the elite athletes with recurrent hamstring injury.

Muscle enthesopathy was more clinically relevant in athletes with high demands on the lower limbs, such as in football and the rugby codes. A pattern of recurrent hamstring injuries began to emerge, often on one side, in patients with vague histories of lower back pain. Recurrent trauma was often present with rare histories of discrete trauma to the buttocks. The importance of the hamstring enthesopathy was relatively under-appreciated in the cohort of patients with established SIJ dysfunction until these elite athletes with recurrent hamstring injury presented for evaluation of possible mechanical dysfunction of the sacroiliac joint.

Examination demonstrated evidence of occult SIJ dysfunction in this group, with a good response to treatment with directed physiotherapy and or prolotherapy (7) / platelet rich plasma injection (8) into the posterior aspect of the joint.

We hypothesised that the hamstring injuries in these elite athletes were due to the altered biomechanics in the pelvis resulting from mechanical dysfunction of the SIJ. A mechanism of the injury was postulated and evidence for 
its utility was proposed and supported by the response to specific therapies.

\section{Materials and Methods}

\subsection{Patients}

Elite athletes with a history of recurrent hamstring injuries and lateralsing lower back pain were referred from multiple centres by orthopedic surgeons, sports physicians and physiotherapists to two sports physicians (JS and MC) with a specialized research interest in lower back pain. Data was collected over a period of 3.5 years. Patients were excluded if there was a history of surgery to the SIJs, prolotherapy or PRP to the joint. All other patients were included. Diagnosis of the hamstring injury was based on history, physical examination and MRI. All patients had undergone extensive rehabilitation of the injury with strengthening exercises plus surgical repair in 4 patients. Recurrent injuries however continued in the cohort of patients. All patients were clinically assessed for mechanical sacroiliac joint dysfunction according to the European guidelines (9) and a clinical score derived from the physical examination. A visual analog pain score (VAS) was obtained at baseline and after frequent follow-up visits after instigation of specific treatment for the SIJ dysfunction. Initial diagnoses of the SIJ dysfunction were confirmed by single photon emission computed tomography of the standard bone scan and fused with $\mathrm{x}$-ray computed tomography (SPECT/ CT) as described elsewhere (5). All patients also underwent baseline and follow-up MRI studies of the hamstring tendons at the conclusion of therapy.

The study was approved by the Institutional Ethics Committee of the University of Notre Dame, Sydney Campus.

\subsection{Treatment}

Initial treatment of the SIJ dysfunction was by directed physiotherapy with review at 6 weeks as described elsewhere $(10,11)$. Briefly, physiotherapy treatment focused on inhibition of muscle recruitment and deficiencies in muscle functional strength. Ultrasound feedback was utilised initially for activation of targeted deep lumbo, pelvic, hip and gluteal muscles, followed by progressed functional strength exercises of key muscle groups to re-establish force closure of the pelvic ring. Therapy was also applied to the primary site of injury, being the dorsal interosseous ligament (DIOL) of the sacroiliac joint. This was achieved with prolotherapy to the ligament with significant improvements in function (7). More recent work with platelet-enriched plasma (PRP) injections into the DIOL also led to significant improvements in symptoms and pain control (8). The major advantage of PRP therapy over dextrose injection was patients required fewer injections (mean of 1.6 versus 3.0), and were able to avoid exposure to radiation as CT guided injections were replaced with ultrasound guided injections for PRP therapy.

\subsection{Statistics}

Statistical analysis was performed using the ANOVA model and paired $t$ test analysis from the Statistical Package for the Social Sciences (SPSS) Version 24 (IBM, New York, USA).

\section{Results}

\subsection{Patients}

The study cohort comprised 23 elite athletes (Rugby Union 8, Rugby league 9, Oz Tag 2, Long-distance runners 2 , Triathletes 2). There were 19 males and 4 females with an average age of 35 years (Range: 22-54 years). Patients reported a mean of 4.2 tears of the hamstring muscle/ tendon (Range 1-10 tears). The average time to diagnosis of the sacroiliac joint dysfunction was 36 months (Range: 3-84 months).

Patients were referred to two sports medicine physicians (JS and MC) for an opinion regarding possible mechanical dysfunction of the SIJ. All 23 patients were found to have SIJ dysfunction with an average clinical score of 6.8 (Range 7-9) (9). Of these cases, 18 were on the right side, 5 on the left with 3 being bilateral. Clinical scores for the diagnosis of sacroiliac joint dysfunction had a mean of 6.8 (Range 6.0-8.0).

\subsection{Imaging}

Patients underwent MRI of the hamstring complex in all instances. The majority also underwent post-treatment MRI before return to sport. Patients reported a mean of 4.2 tears of the hamstring muscle/ tendon (Range 1->10 tears). Three patients reported bilateral hamstring tears, 15 were left sided and 5 right sided.

The sacroiliac joint dysfunction was assessed by fused single photon emission computed tomography (SPECT) of the bone scan with x-ray computed tomography (CT). Imaging findings indicated the right SIJ as the primary site of dysfunction in 15, left in 6 and both joints in 2 . The dominant hamstring enthesopathy was left-sided in 18 and on the right in 5 .

\subsection{Treatment Response}

Of 23 patients treated with physiotherapy alone, 4 had a good enough response to return to elite sport. The remainder had partial or no response with persistent pain at 
the site of the hamstring injury. These patients were switched to PRP injection under ultrasound guidance. The sacroiliac joint that was the dominant side of dysfunction based on the SPECT/ CT findings and clinical assessment was injected with PRP twice. The baseline VAS score was a mean of 80.0 (Range 65.0-90.0). Following treatment, the mean score was 9.0 (Range 0-50.0). The paired t test confirmed a significant improvement in the VAS scores following treatment $(\mathrm{p}=0.002)$.

\section{Discussion}

This study provides a linkage between mechanical dysfunction of the sacroiliac joint and alterations in muscle function around the pelvis which has the potential to lead to recurrent injuries of the hamstring muscles in elite athletes. It extends a series of observations that included hamstring tendon enthesopathy in patients with SIJ dysfunction (6) to specific physical injury to the tendon and muscle itself under high-level athletic activity. The improvements in the VAS scores were highly significant and more importantly, most athletes were able to return to their chosen sport at an elite level. However, unlike the general non-athletic population, $80 \%$ of whom improve with directed physiotherapy (7), only 4 elite athletes responded to conservative treatment and the majority required intervention with PRP injection. It indicates more severe injury to the SIJ and hence the chain reaction of abnormal muscle sequencing and proclivity to injury.

Mechanical dysfunction of the sacroiliac joint was described as long ago as 1905 (12). The concept was lost from medical consciousness with publication of the citation classic on the importance of the intervertebral disc as a cause of back pain in 1934 (13). The importance of the condition as a cause of lateralising low back pain with a pain distribution identical to intervertebral disc prolapse slowly re-entered medical consciousness in the 1990s and 2000s. This was precipitated by initial work published by Solonen in 1957 (14), with subsequent recognition of the joint as a source of low back pain in pregnancy (15). Multiple authors published on the condition (16-19) with evidence-based validation of clusters of physical tests culminating in publication of the European guidelines for a firm clinical diagnosis in 2008 (9).

Knowledge of the anatomy is crucial in understanding the relationship between mechanical dysfunction of the sacroiliac joint and hamstring tears. The primary function of the pelvis during weight-bearing is to transfer the loads generated by body weight and gravity from the spine to the lower limbs (20). The SIJ joints are relatively stable, yet flexible enough to absorb the changing forces across the joint. Ligamentous structures that surround each SIJ and the pubic symphysis create both tensile and compressive forces across the joint that limit the range of intrapelvic motion $(21,22)$. The flexibility is a result of the inter-relationship between the muscles, their internal fascial and complex external fascial elements that lead to a web of synchronised support for the pelvis (22). While the sacroiliac joint is L-shaped it has a longer horizontal then vertical arm. A tubercle on the iliac side locks into a concavity on the auricular portion of the sacrum, dorsal to the joint. This is the axis of movement of the joint (S2), allowing nutation (forward rotation) and counter-nutation (backward rotation). Irregularities in the joint surfaces and the wedge-like shape help lock the sacrum between the two iliac bones in a keystone configuration (22).

Sequential contraction of muscles, muscle groups and the fascial attachments (23) allow the co-ordinated "force closure" of the pelvic ring, helping reinforce the "form closure" of the two iliac bones around the sacrum (11). It is this combination that allows both stability and flexibility in order to handle the forces generated by ambulation and other movements (24). The contribution of muscle force to stabilisation of intrapelvic motion is based upon optimal patterning and activation of local and global muscles together with the synergistic tensioning of ligamentous structures that principally increase the stiffness of the sacroiliac joint prior to weight transfer $(11,25,26)$.

There are multiple ligaments that support the SIJ (22). Core ligaments are numerous and include the ventral, dorsal and interosseous ligaments and the associated short and long dorsal sacroiliac ligaments. The dorsal interosseous ligament (DIOL) is the strongest supporting ligament of the joint and fills in the space that is dorsal and cephalad to the synovial portion of the joint (mainly at the $\mathrm{S} 1$ and S2 levels). This allows the sacrum to sit in a stable configuration between the iliac bones and allows anterior motion into the pelvic ring (nutation - mainly due to contraction of the erector spinae and gluteus maximus) with sequential abdominopelvic muscle contraction closing the pelvic ring. Sturesson et al (20) have shown that nutation of the sacrum occurs bilaterally when the spine is loaded vertically with counter-nutation of the sacrum or anterior rotation of the iliac bone being a relatively less stable position for the SIJ, which subsequently causes loading onto the long dorsal sacroiliac ligament (27). The stability of the sacroiliac joint is enhanced by the wedge angle of the joint and the coefficient of friction of the roughened surfaces of the sacral and iliac articular surfaces (28). This effectively creates a self-bracing effect of the joint that relieves some of the stress on the ligaments that support it. One of the most important structures that influences the self-bracing mechanism is the sacrotuberous ligament and by implication, the muscles that are connected to or converge on it $(29,30)$. While the cranial portion of the sacrum can rotate anteriorly around the S2 axis, this motion is restricted by the sacrospinous and sacrotuberous ligaments (Figure 1) (22). Counter-nutation (posterior movement of the sacrum) is restricted by the long dorsal ligament (22). Any injury that leads to abnormal movement of the sacroiliac joint can alter the 
information sent from mechanoreceptors receptors at the articular surface of the joint to the brain (31) and this may explain the pattern of inhibition of the transversus abdominis, multifidus and ipsilateral gluteus maximus which is commonly reported with SIJ dysfunction (25). When the SIJ is injured, there is significant alteration in intra-pelvic motion and the sacroiliac joint glide. The chain reaction is a linkage to altered lumbopelvic muscle activation $(25,27,32,33)$. If the SIJ is no longer able to maintain its closed pack position with weight-bearing, it essentially unlocks with anterior rotation of the iliac bone and sacral counter-nutation $(25,34)$. This transmits increased strain onto the long dorsal sacroiliac ligament, creating pain in the ipsilateral buttock that is often described as worse when weight-bearing. Normal recruitment of abdominopelvic and hip muscle contraction that aid dynamic closure of the pelvic ring is disrupted by chronic pain. Local lumbo-pelvic muscle activation may be inhibited while global muscle activation becomes more tonic. Maladaptive strategies are applied with muscle splinting and bracing in an attempt to increase pelvic force closure (35). There is some evidence that hamstring spasm may accompany the dysfunction in a reflex attempt to stiffen the joint (force closure) (36).

Under the circumstances of sacroiliac joint dysfunction, there will be increased tension on the ipsilateral long dorsal ligament to stop counter-nutation. There will also be relative tension on the sacrotuberous/ sacrospinous ligament complex on the contralateral side to prevent relative over-nutation of the other side of the sacrum. Changes on the contralateral side resulting from increased tension in the sacrotuberous ligament will be transmitted to the tendon of the long head of the biceps femoris muscle which is fused with the sacrotuberous ligament in approximately $50 \%$ of cases (29). Van Wingerden et al (39) have shown a dynamic relationship between the two structures depending on whether in the flexed or erect position, leading to changes in torque that influence sacroiliac joint stability. The thrust of this work was to explore the effect of hamstring muscle contraction on the sacrotuberous ligament (Figure $1 \& 2$ ). We would postulate that increased tension in the sacrotuberous ligament most likely leads to increased tension in the hamstring tendon/ muscle that will predispose it to injury with rapid increases in dynamic tension as occurs in many elite running and kicking sports (Figure 3, $4 \& 5$ ). The majority of the hamstring injuries were on the contralateral side to the sacroiliac joint dysfunction, providing support for this hypothesis. Improvements in pain scores and functional parameters allowing return to sport following treatment provides further support for this contention. What of injuries to the hamstring muscle complex on the ipsilateral side of the sacroiliac joint dysfunction?

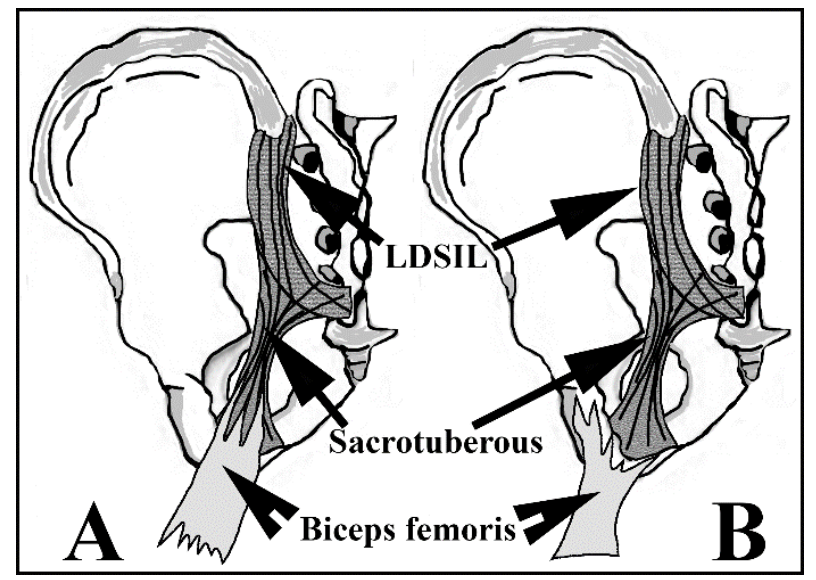

Figure 1. Graphic illustrates the contiguous nature of the sacrotuberous and long dorsal sacroliliac ligaments. Panel A shows that the biceps femoris tendon may be contiguous with the sacrotuberous ligament in a proportion of patients or have a discrete insertion into the ischial tuberosity (Panel B). This concept is demonstrated in the MRI studies in Figure 2. 


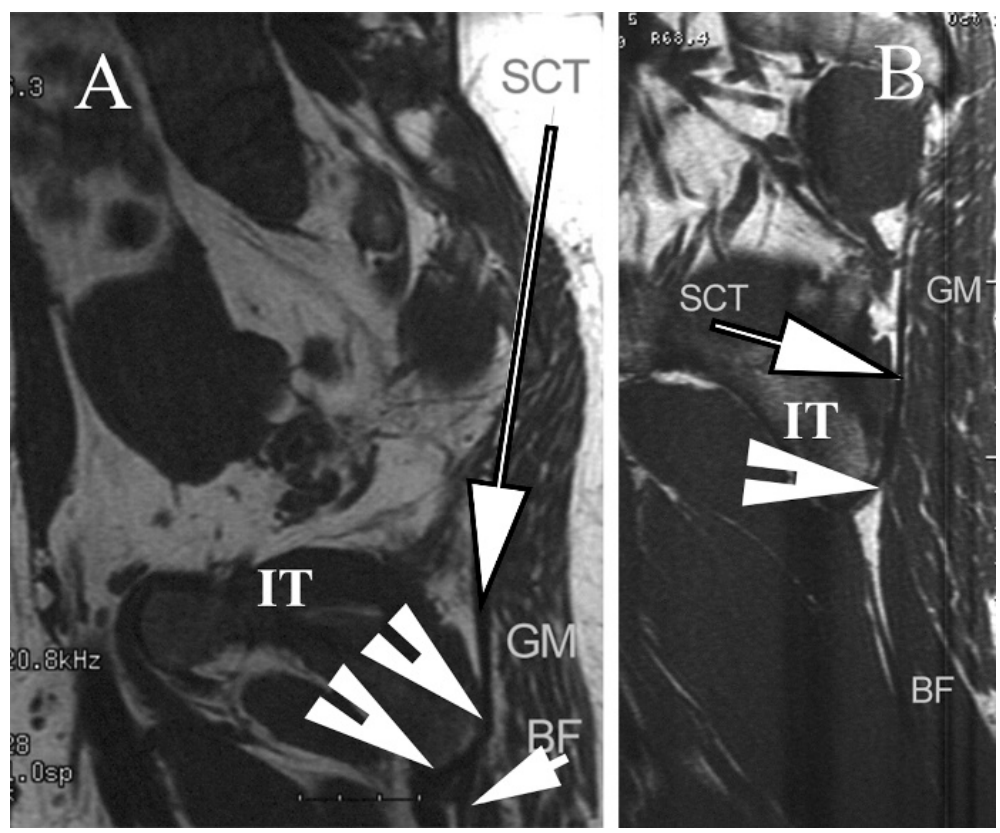

Figure 2. These two MRI studies demonstrate the continuity (arrowheads) of the sacrotuberous ligament and the biceps femoris tendon (arrow) in Panel A together with their connection to the ischial tuberosity (IT). Panel B demonstrates discrete attachments of the sacrotuberous ligament (arrow) and the biceps femoris tendon (arrowhead) on the ischial tuberosity (IT)

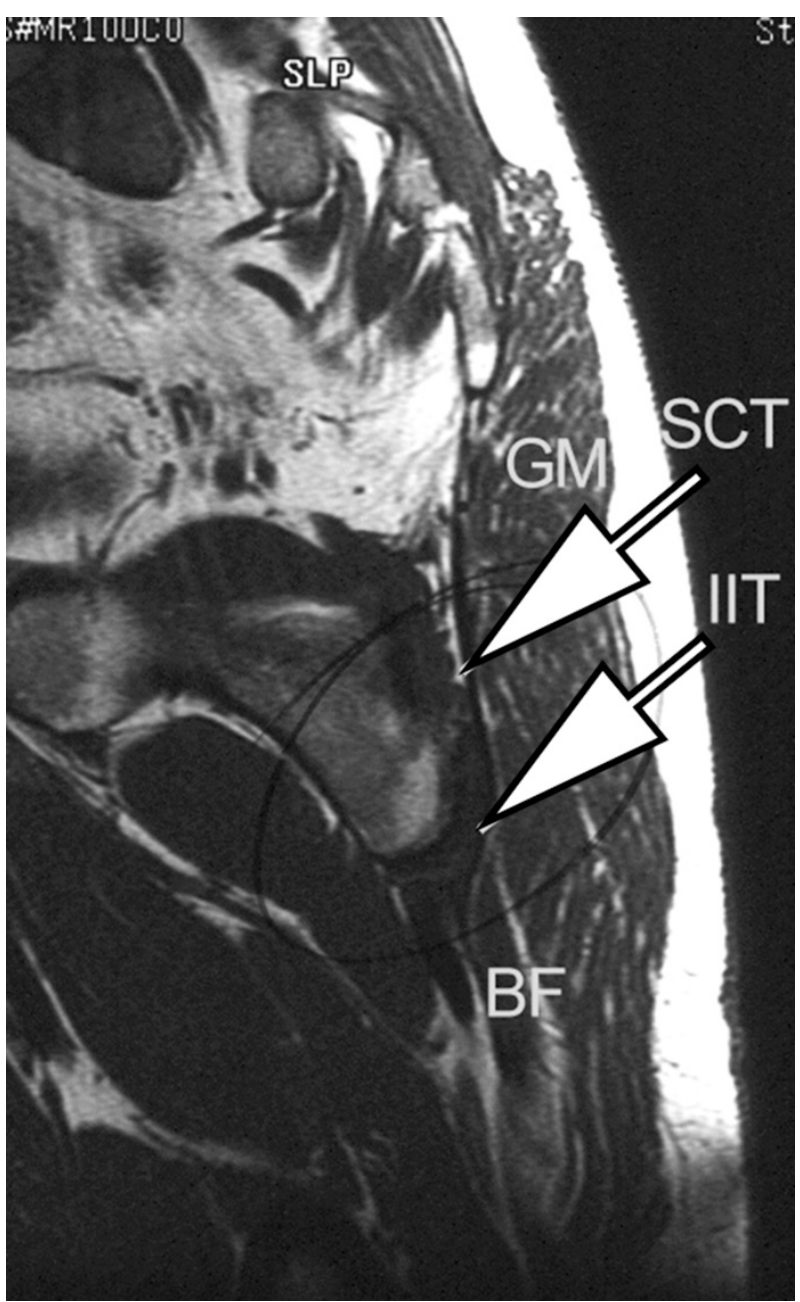

Figure 3. The MRI study demonstrates bone marrow oedema around the site of insertion of the biceps femoris tendon (arrows) into the ischial tuberosity. In this instance, there is continuity of the biceps femoris tendon and the sacrotuberous ligament (upper arrow) 


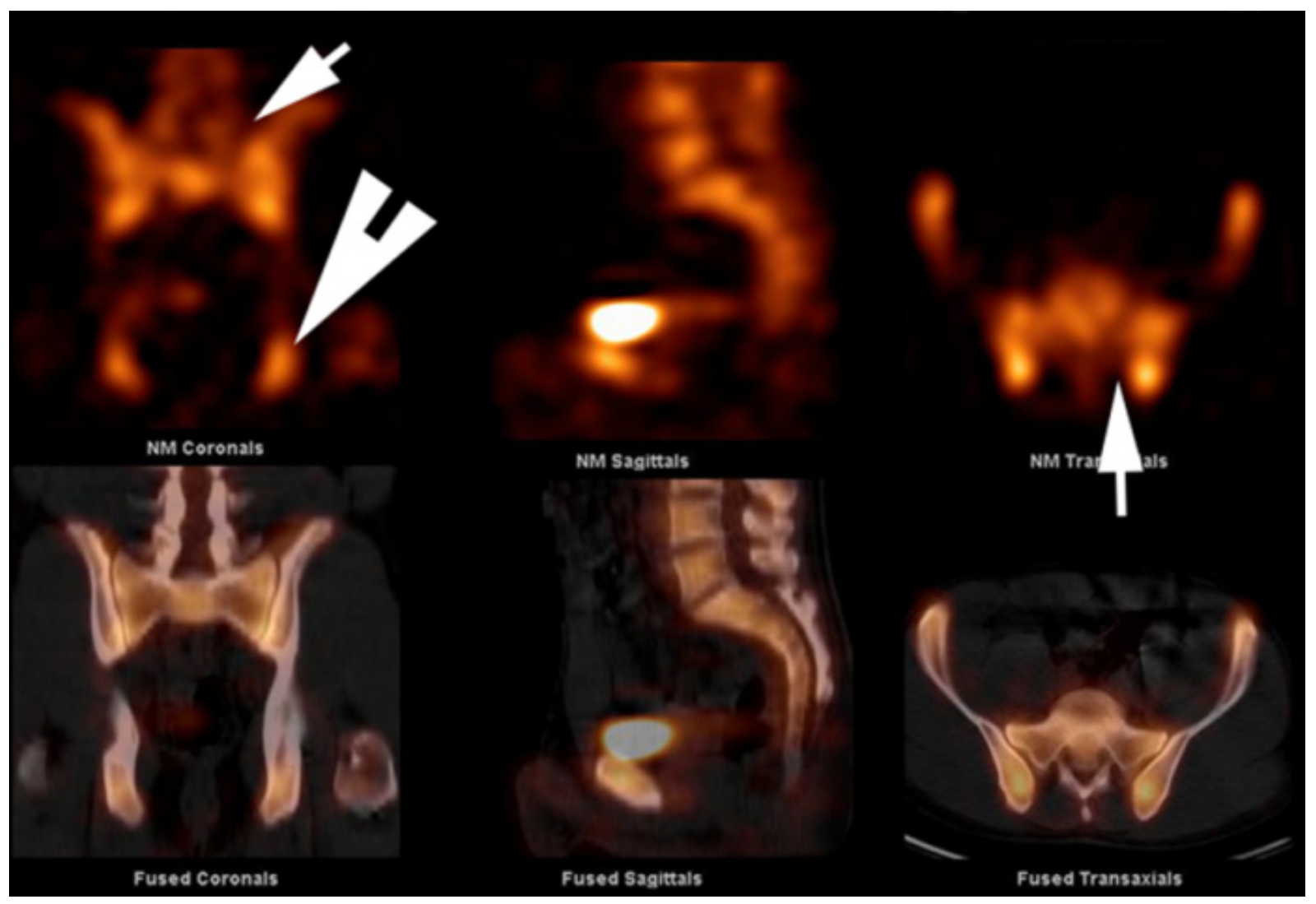

Figure 4. SPECT/CT images of a patient with recurrent hamstring tears on the left side. The arrow in the scintigraphic study shows increased uptake of tracer in the left dorsal interosseous ligament. The arrowhead indicates the site of increased uptake in the ischial tuberosity at the site of insertion of the left hamstring tendon. This patient's MRI is shown in Figure 5

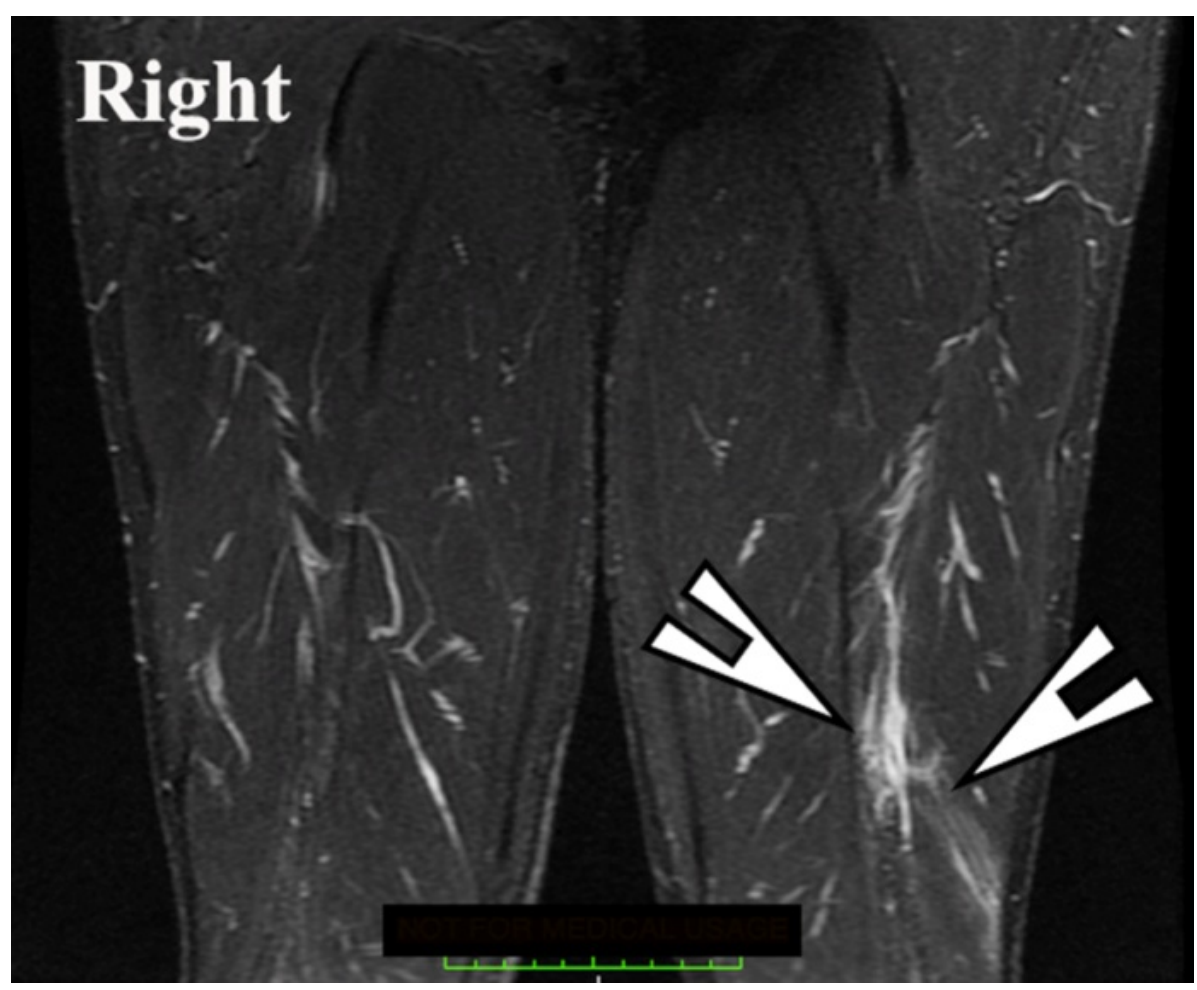

Figure 5. MRI study of the patient was showed in Figure 4. The patient was an elite rugby league player who had sustained recurrent tears of the left hamstring muscle and tendon and also gave a vague history of left buttock pain and recurrent trauma during play. The study demonstrates high signal from multiple tears in the body of the left hamstring muscle (arrowheads). The patient responded well to targeted physiotherapy for the causative left sacroiliac joint incompetence 
One could hypothesis that the forces applied to the pelvis are dynamic and ultimately a balancing act. A proportion of patients will have direct fascial connection between the sacrotuberous ligament and tendon of the long head of biceps on both sides $(\sim 30 \%)(29)$. The long dorsal sacroiliac ligament merges with the lateral edge of the sacrotuberous ligament as it descends from the origin on the posterior superior iliac crest (Figure 1) $(40,41)$. This ligament is under increased tension as the pelvis rotates anteriorly (counter-nutation) following injury and dysfunction of the sacroiliac joint. The tension may be transmitted to the ipsilateral sacrotuberous ligament and thereby to the ipsilateral hamstring, predisposing it to recurrent injury. Again, the evidence to support this contention is in the reduction in pain and improvement in function with treatment of the sacroiliac joint dysfunction in the group of patients in this study.

The main purpose of treatment is to maintain a stable closed-pack alignment during weight-bearing activities in order to enable optimal load transfer through the pelvis. This therefore incorporates retraining lumbo-pelvic stability. Treatment must be tailored to fit four generalised subgroups $(5,27,42)$. Treatment should be aimed at SIJ dysfunction due to reduced force closure, excessive force closure, articular injury and extra-articular injury to the ligamentous support network. Treatment is therefore based on a high degree of specificity in assessment and diagnosis in order to use the right therapy, be it manual, exercise, cognitive or combination of all three. Specialised physiotherapy generally deals with the abnormalities in lumbopelvic and hip muscle recruitment, muscular strength deficiencies and tendinopathy, plus functional strength rehabilitation. In some circumstances as with the majority of cases in this study, the injury to the dorsal interosseous ligament of the sacroiliac joint is too extensive and direct therapy to the ligament must be utilised. This has been achieved with prolotherapy to the ligament with significant improvements in function (7). More recently, platelet-enriched plasma (PRP) injections into the DIOL have also led to significant improvements in symptoms and pain control. Saunders et al (8) presented data on 45 patients who had ultrasound-guided injection into the dorsal interosseous ligament of the SIJ. The group was compared to a similar cohort of historical controls treated with prolotherapy by the same group (7). Subjects treated with PRP demonstrated equivalent results at 3 and 12 months with a mean of 1.6 injections versus 3.0 injections in the prolotherapy group. Surgical fusion of the sacroiliac joint is generally considered a last resort, especially in elite athletes and is reliant on centres that undertake the procedure on a relatively frequent basis (43).

When should suspicion of sacroiliac joint dysfunction arise in patients with hamstring injuries? Recurrent injury of the same hamstring is usually the major warning sign. Suspicion may arise from the history of lateralising lower back or buttock pain in the same patient, especially with no imaging evidence of intervertebral disc prolapse. There may be a history of significant trauma to the lower back or buttocks. The clinical examination may yield the diagnosis or suspicion of such an injury, but may be the domain of specialised sports physicians.

Imaging is usually the next sequence. An MRI should be routinely obtained in the case of acute proximal hamstring injuries in order to rule out an avulsion injury from the proximal attachment of the hamstrings to the ischial tuberosity (Figure 6). MRI is useful in determining multiple characteristics of hamstring injuries, including the size and extent of the injury (length and volume), the specific muscle involved (semitendinosus, semimembranosus, and/or biceps femoris - short and long head), the location of the injury (proximal versus distal injuries and muscle-belly injury versus musculotendinous injuries versus intratendinous injuries), and the signal intensity of injuries. MRI will not however yield the diagnosis of sacroiliac joint dysfunction, as has been shown by a number of authors $(44,45)$. Bone scintigraphy with SPECT/ CT has been shown to be a valid diagnostic modality as it also demonstrates enthesopathy and secondary femeroacetabular hip impingement $(5,6)$. 


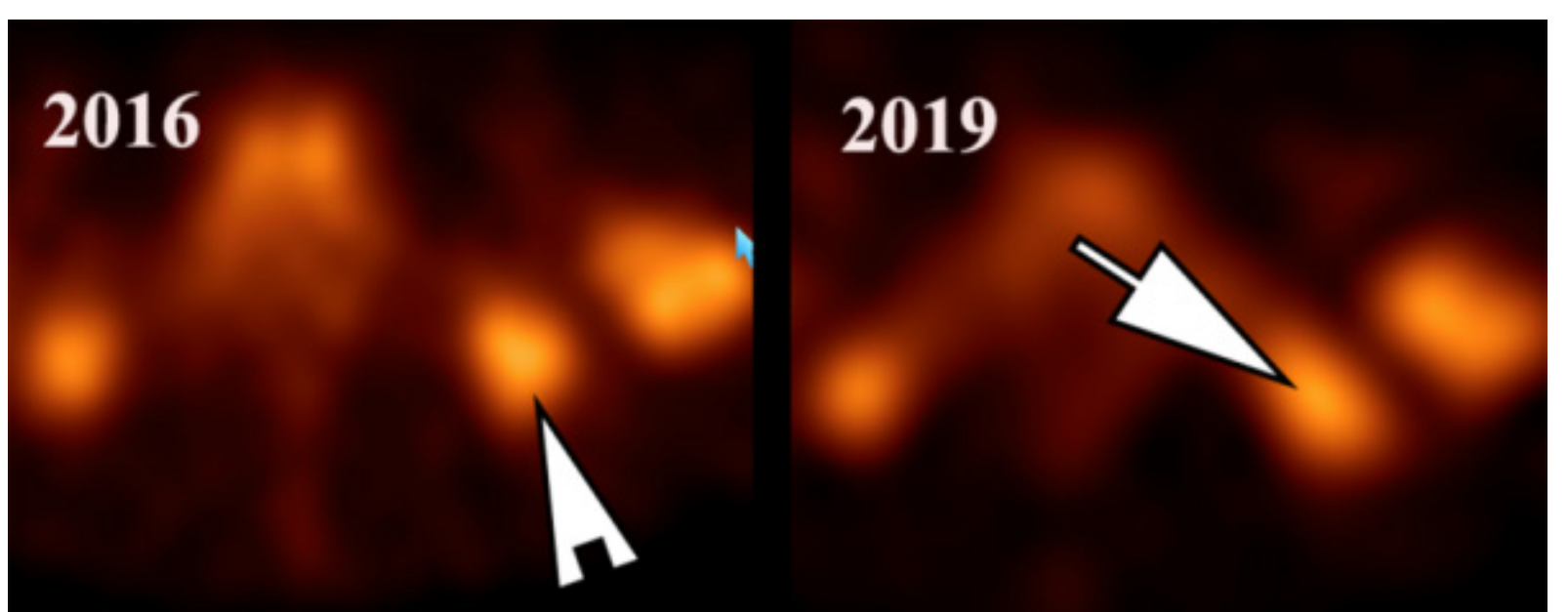

NM Transaxials
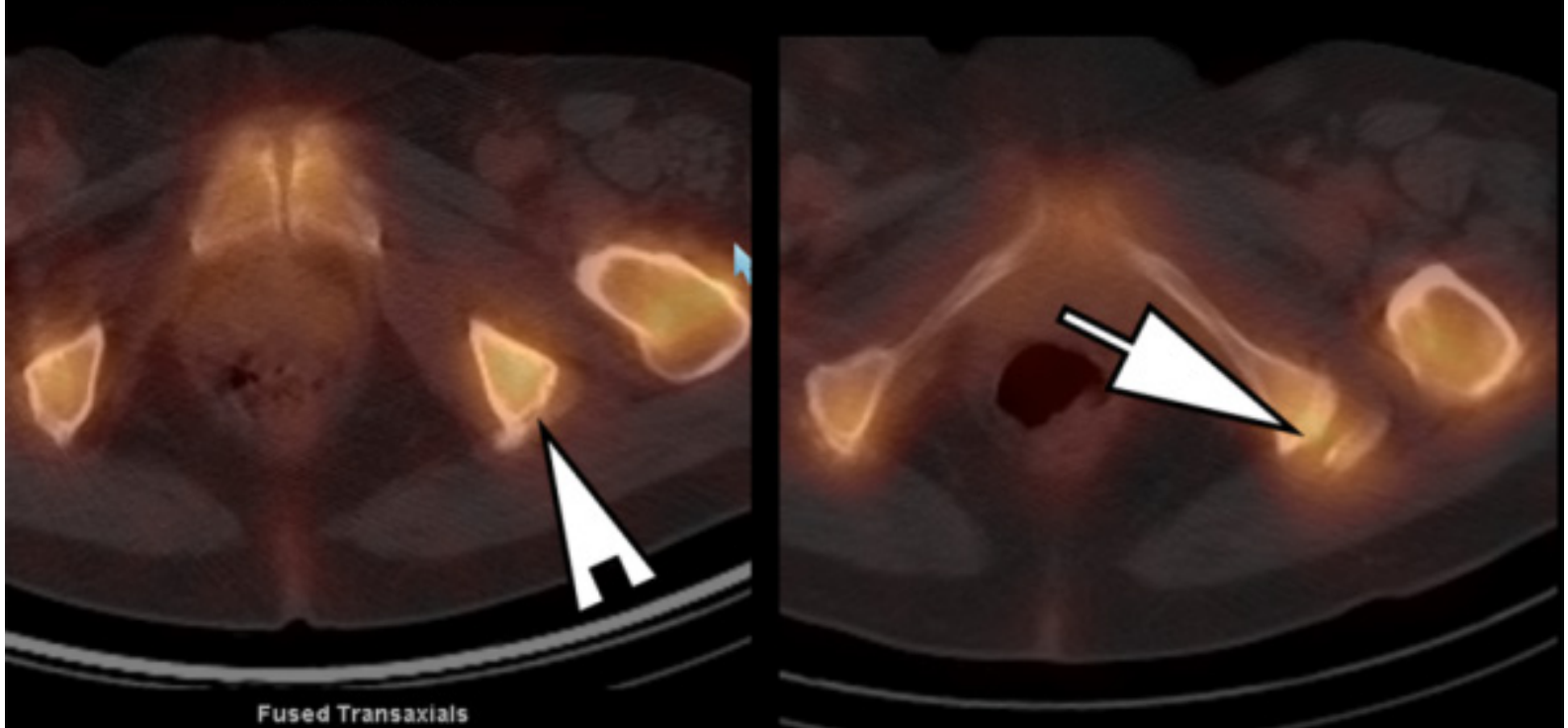

Figure 6. SPECT/CT images of a patient initially diagnosed with left sacroiliac joint incompetence in 2016 for which therapy was not undertaken. Three years later, the patient presented with acutely increasing left buttock pain after falling down stairs. The sequence of images demonstrates enthesopathy at the site of the left hamstring tendon insertion into the ischial tuberosity in 2016 and the subsequent avulsion of the tendon from the tuberosity in 2019 


\section{Conclusions}

Recurrent hamstring injuries are common in a number of elite sporting endeavours. Recurrence on the same side should raise suspicion of possible injury to the sacroiliac joint, especially in contact sports. The diagnosis should be suspected where there is a history of trauma to the lower back or buttocks or there is a history of lateralising lower back pain without imaging evidence of a significant or culprit intervertebral disc prolapse. Treatment of the sacroiliac joint dysfunction is usually successful in approximately $80 \%$ of cases with specialised physiotherapy. If physiotherapy is unsuccessful, then alternative therapies such as prolotherapy or PRP injection into the DIOL under imaging guidance can also yield good results and a return to sport.

\section{Conflict of Interest Statement}

a. None of the authors have Competing Interests

b. No Funding or grants or equipment were provided for the project from any source.

c. There are no financial benefits to the authors from publication of this manuscript.

d. Details of any previous presentation of the research, manuscript, or abstract in any form. Abstract to be presented at the World Congress of Low back pain in Antwerp in 2019.

\section{REFERENCES}

[1] J. H. Brooks, C. W. Fuller, S. P. Kemp, D. B. Reddin. Incidence, risk, and prevention of hamstring muscle injuries in professional rugby union. American Journal of Sports Medicine, Vol 34, No. 8, 1297-1306. 2006.

[2] H.M. De Visser, M. Reijman, M.P. Heijboer, P.K. Bos. Risk factors of recurrent hamstring injuries: a systematic review. British Journal of Sports Medicine, Vol 46, 124-130. 2012.

[3] G. Koulouris, D. A. Connell, P. Brukner, M. Schneider-Kolsky. Magnetic resonance imaging parameters for assessing risk of recurrent hamstring injuries in elite athletes. American Journal of Sports Medicine, Vol 35, No. 9, 1500-1506. 2007.

[4] N. Malliaropoulos, T. Isinkaye, K. Tsitas, N. Maffulli. Reinjury after acute posterior thigh muscle injuries in elite track and field athletes. American Journal of Sports Medicine, Vol 39, No. 2, 304-310. 2011.

[5] M. Cusi, J. Saunders, H. Van der Wall, I. Fogelman. Metabolic disturbances identified by SPECT-CT in patients with a clinical diagnosis of sacroiliac joint incompetence. European Spine Journal, Vol 22, No. 7, 1674-1682. 2013.

[6] J. Saunders, M. Cusi, H. Van der Wall. What's old is new again: The sacroiliac joint as a cause of lateralising low back pain. Tomography, Vol 4, No. 2, 72-77. 2018.

[7] M. Cusi, J. Saunders, B. Hungerford, T. Wisbey-Roth, P. Lucas, S. Wilson. The use of prolotherapy in the sacroiliac joint. British Journal of Sports Medicine, Vol 44, No. 2, 100-104. 2010.

[8] J. Saunders, M. Cusi, L. Hackett, H. Van der Wall. A comparison of ultrasound guided PRP injection and prolotherapy for mechanical dysfunction of the sacroiliac joint. J Prolotherapy, Vol 10, No., e992-e999. 2018.

[9] A. Vleeming, H. B. Albert, H. C. Ostgaard, B. Sturesson, B. Stuge. European guidelines for the diagnosis and treatment of pelvic girdle pain. European Spine Journal, Vol 17, No. 6, 794-819. 2008.

[10] M. Laslett. Evidence-Based Diagnosis and Treatment of the Painful Sacroiliac Joint. J Manual and Manipulative Therapy, Vol 16, No., 142-152. 2008.

[11] D. G. Lee, A. Vleeming. An integrated therapeutic approach to the treatment of pelvic girdle pain. In: Vleeming A, Mooney V, Stoeckart R, eds. Movement, stability \& lumbopelvic pain. London: Elsevier: 621. 2007.

[12] J. E. Goldthwaite, R. B. Osgood. A consideration of the pelvic articulation from an anatomical, pathological, and clinical standpoint. Boston Medical and Surgical Journal, Vol 152, No., 593-601. 1905.

[13] W. J. Mixter, J. Barr. Rupture of the intervertebral disc with involvement of the spinal canal. New England Journal of Medicine, Vol 11, No., 210-215. 1934.

[14] K. A.Solonen. The sacro-iliac joint in the light of anatomical, roentgenological and clinical studies. Acta Orthopaedica Scandinaviae Supplement, Vol 27, No., 1-127. 1957.

[15] G. Berg, M. Hammar, J. Möller-Nielsen. Low back pain during pregnancy. Obstetetrics and Gynecology, Vol 71, No., 71-75. 1988.

[16] H. C. Ostgaard, G. B. J. Andersson, K. Karlsson. Prevalence of back pain in pregnancy. Spine, Vol 1991, No. 16, 549-552. 1991

[17] C. J. Snijders, R. Stoeckart, Vleeming A. Transfer of lumbosacral load to iliac bones and legs Part 1: Biomechanics of self-bracing of the sacroiliac joints and its significance for treatment and exercise. Clinical Biomechanics, Vol 8, No. 6, 285-294. 1993.

[18] C. J. Snijders, R. Stoeckart, A. Vleeming. Transfer of lumbosacral load to iliac bones and legs Part 2: Loading of the sacroiliac joints when lifting in a stooped posture. Clinical Biomechanics, Vol 8, No. 6, 295-301. 1993.

[19] A. C. Schwarzer, C. D. Aprill, N. Bogduk. The Sacroiliac Joint in Chronic Low Back Pain. Spine, Vol 20, No. 1, 31-37. 1995.

[20] B. Sturesson, A. Uden, A. Vleeming. A radiostereometric analysis of movements of the sacroiliac joints during the standing hip flexion test. Spine (Phila Pa 1976), Vol 25, No. 3, 364-368. 2000.

[21] F. H.Willard. The muscular, ligamentous and neural structure of the lumbosacrum and its relationship to low back pain. In: A Vleeming, V. Mooney, R. Stoeckart, eds. Movement, Stability \& Lumbopelvic Pain. Integration of 
research and therapy. London: Churchill Livingstone Elsevier: 658. 2007.

[22] A. Vleeming, M. D. Schuenke, A. T. Masi, J. E. Carreiro, L. Danneels, F. H. Willard. The sacroiliac joint: an overview of its anatomy, function and potential clinical implications. Journal of Anatomy, Vol 221, No. 6, 537-567. 2012.

[23] R. Kissling, H. Jacob. The mobility of the sacroiliac joint in healthy subjects. Bulletin of Hospital for Joint Disease, Vol 54, No. 3, 158-164. 1996.

[24] C. Lovejoy. Evolution of human walking. Sci Am, Vol 259, No., 118-125. 1988.

[25] B. Hungerford, W. Gilleard, P. Hodges. Evidence of Altered Lumbopelvic Muscle Recruitment in the Presence of Sacroiliac Joint Pain. Spine, Vol 28, No. 14, 1593-2000. 2003.

[26] C. A. Richardson, C. J. Snijders, J. A. Hides, L. Damen, J. Storm. The Relation between the Transversus Abdominis Muscles, Sacroiliac Joint Mechanics, and Low Back Pain. Spine, Vol 27, No. 4, 399-405. 2002.

[27] D. Lee. The Pelvic Girdle. London: Churchill Livingstone, 2004.

[28] A. Vleeming, A. C. W.Volkers, C. J. Snijders, R. Stoeckart. Relation between form and function in the sacroiliac joint. Part II: biomechanical aspects. Spine, Vol 15, No. 2, 133-136. 1990

[29] A. Vleeming, R. Stoeckart, C. Snijders. The sacrotuberous ligament: a conceptual approach to its dynamic role in stabilising the sacroiliac joint. Clinical Biomechanics, Vol 4, No. 4, 201-203. 1989.

[30] A. Vleeming, J. Van Wingerden, C. Snijders, R. Stoeckart, T. Stijnen. Load application to the sacrotuberous liga- ment; influences on SI-joint mechanics. Clinical Biomechanics, Vol 4, No., 204- 2091989.

[31] A. Indahl, A. Kaigle, O. Reikeras, S. Holm. Sacroiliac joint involvement in activation of the porcine spinal and gluteal musculature. Journal of Spinal Disorders, Vol 12, No. 4, 325-330. 1999.

[32] B. Hungerford, W. Gilleard, D. Lee. Altered patterns of pelvic bone motion determined in subjects with posterior pelvic pain using skin markers. Clinical Biomechanics (Bristol, Avon), Vol 19, No. 5, 456-464. 2004.

[33] P. B. O'Sullivan, D. J. Beales, J. A. Beetham, et al. Altered Motor Control Strategies in Subjects With Sacroiliac Joint Pain During the Active Straight-Leg-Raise Test. Spine, Vol 27, No. 1, E1-E8. 2002.

[34] J. M. A. Mens, A. Vleeming, C. J. Snijders, H. J. Stam, A. Z. Ginai. The active straight leg raising test and mobility of the pelvic joints. European Spine Journal, Vol 8, No. 6, 468-473. 1999.

[35] A. Huson. Kinematic models and the human pelvis. In: Vleeming A, Mooney V, Stoeckart R, eds. Movement, Stability and Lumbopelvic Pain: Integration of Research and Therapy. Edinburgh: Churchill Livingstone, 159-166. 2007.

[36] J. P. Van Wingerden, A. Vleeming, H. M. Buyruk, K. Raissadat, 13:199-205. Stabilization of the sacro-iliac joint in vivo: verification of muscular contribution to force closure of the pelvis. Eur Spine J, Vol 13, No. 3, 199-205 2004.

[37] L. Damen, H. Buyruk, F. Guler-Uysal, e. al. The prognostic value of asymmetric laxity of the sacroiliac joints in pregnancy related pelvic pain. . Spine (Phila Pa 1976), Vol 27, No., 2820-2824. 2002.

[38] A. Vleeming, H. J. De Vries, J. Mens, J.P. Van Wingerden. Possible role of the long dorsal sacroiliac ligament in women with peripartum pelvic pain. Acta Obstetricia et Gynecologica Scandinavica, Vol 8`, No. 5, 430-436. 2002.

[39] J. P. van Wingerden, A. Vleeming, C. J. Snijders, R. Stoeckart. A functional-anatomical approach to the spine-pelvis mechanism: interaction between the biceps femoris muscle and the sacrotuberous ligament. European Spine Journal, Vol 2, No. 3, 140-144. 1993.

[40] A. Vleeming, H. J. de Vries, J. M. Mens, J. P. van Wingerden. Possible role of the long dorsal sacroiliac ligament in women with peripartum pelvic pain. Acta Obstetricia et Gynecologica Scandinavica, Vol 81, No. 5, 430-436. 2002.

[41] A. Vleeming, A. L. Pool-Goudzwaard, D. Hammudoghlu, R. Stoeckart, C. J. Snijders, J. M. Mens. The function of the long dorsal sacroiliac ligament: its implication for understanding low back pain. Spine (Phila Pa 1976), Vol 21, No. 5, 556-562. 1996.

[42] D. J. Beales, P. B. O'Sullivan, N. K. Briffa. The effects of manual pelvic compression on trunk motor control during an active straight leg raise in chronic pelvic girdle pain subjects. Manual Therapy, Vol 15, No. 2, 190-199. 2010.

[43] H. A. Zaidi, A. J. Montoure, C. A. Dickman. Surgical and clinical efficacy of sacroiliac joint fusion: a systematic review of the literature. Journal of Neurosurgery: Spine, Vol 23, No. 1, 59-66. 2015

[44] A. Hansen, D. V. Jensen, E. C. Larsenet al. Postpartum pelvic pain--the "pelvic joint syndrome": a follow-up study with special reference to diagnostic methods. Acta Obstetricia et Gynecologica Scandinavica, Vol 84, No. 2, 170-176. 2005.

[45] K. B. Puhakka, F. Melsen, A. G. Jurik, L. W. Boel, A. E Vesterby. MR imaging of the normal sacroiliac joint with correlation to histology. Skeletal Radiology, Vol 33, No. 1, 15-28. 2004. 